\title{
Design of an Economical Iot Based Intelligent Lake Water Quality Measuring System with of the Shelf Industrial Grade Sensors
}

\author{
Anupreet Dube, Jayesh Trivedi, Yogendra Singh Solanki, Aaditya Maheshwari, Abhishek Sharma
}

\begin{abstract}
The paper presents an IOT based intelligent lake water quality measuring system that comprises of low cost industrial grade sensors and off the shelf components along with signal conditioning circuits that measure the important water quality parameters such as $\mathrm{DO}, \mathrm{pH}, \mathrm{TDS}$, and Temperature. The data is pushed onto a dedicated cloud platform in real-time and can be accessed through an online dashboard, as well as from an android application on smart phones. The system is also equipped with very important feature: the detection of abnormal dynamic variation in measured parameters and anomaly alert algorithm. The system firmware has intelligence that modulates the data transmission rate to cloud for extending the battery life, based on ambient lighting conditions and optimizes the rate in case of anomaly in water quality parameters to optimize the use of battery power. The system has two variants, the first variant has a fixed structure that can be affixed to a structure at any selected location preferably the shore, whereas the second one has a floating structure that can remain afloat on the water surface. System architecture is described and the measured water quality parameters are presented of tests conducted at multiple lakes in different weather conditions. The results have been verified with standard laboratory test results and presented here.
\end{abstract}

Keywords: IoT, Remote sensing, ambient lighting detection, Dynamic transmission rate, Anomaly alert.

\section{INTRODUCTION}

Water is the most essential necessity for all lifeforms for their survival. In this era of extensive deployment of industries in rural as well as urban sectors, the waste management techniques adopted by the industries has led to degradation of the water quality of nearly all water bodies around the globe. In most instances, water is extremely unfit not only for drinking but also for all kinds of water use cases.

This paper describes an IOT based intelligent lake water quality monitoring system that comprises of low cost industry grade sensors and off the shelf components along with signal conditioning circuits that measure the important water quality parameters.

Revised Manuscript Received on March 15, 2020.

Anupreet Dube*, Techno India NJR Institute of Technology, Udaipur, Rajasthan, India.

Jayesh Trivedi, Techno India NJR Institute of Technology, Udaipur, Rajasthan, India.

Yogendra Singh Solanki, Techno India NJR Institute of Technology, Udaipur, Rajasthan, India.

Aaditya Maheshwari, Techno India NJR Institute of Technology, Udaipur, Rajasthan, India.

Abhishek Sharma, Techno India NJR Institute of Technology, Udaipur, Rajasthan, India.
The data is pushed onto a dedicated cloud platform in real-time and can be accessed through an online dashboard, as well as from an android application on smart phones.

The water quality parameters measured by this system are:

\section{1. $\mathbf{p H}$}

$\mathrm{pH}$ is the scale used to determine the acidity $(\mathrm{pH}<7)$ or basicity $(\mathrm{pH}>7)$ of water-based solutions. The $\mathrm{pH}$ for surface water ranges from 6.5 to 8.5 and for groundwater is between 6.0 and 8.5. The ideal value of $\mathrm{pH}$ for potable water is between 6.0 and 8.0 .

\section{Total Dissolved Solids (TDS)}

Total dissolved solids (TDS) is a measure of the dissolved particles present in a liquid. Ideal value of TDS for potable water is less than 300ppm. The TDS must not exceed 900ppm.

\section{Temperature}

The ideal potable water temperature is $15^{\circ} \mathrm{C}$.

\section{Dissolved Oxygen (DO)}

Dissolved oxygen in water bodies is essential for survival of aquatic lifeforms.

DO sensor measures the oxygen dissolved in water as $\mathrm{mg} / \mathrm{L}$ or as a percent dissolved oxygen (\%DO). DO value for healthy water must be above $6.5-8 \mathrm{mg} / \mathrm{L}$ or between $80-120 \%$

\section{SYSTEM ARCHITECTURE}

The Lake water quality measuring system is equipped with the following hardware elements:

\section{A.Solar Panel}

The solar panel has maximum output power of $50 \mathrm{Watts}$. The values of output current and voltage at maximum power are $2.83 \mathrm{~A}$ and $17.0 \mathrm{~V}$ respectively.

\section{B.Light Sensor}

The Light sensor scans the ambient lighting conditions and regulates the data transmission rate of the system accordingly. It is a light dependent photo resistor whose resistance is inversely dependent on the amount of light falling on it.

\section{C.Water quality measuring sensors}

The sensors used are industrial grade sensors which have very high precision and accuracy. The details are as follows: 


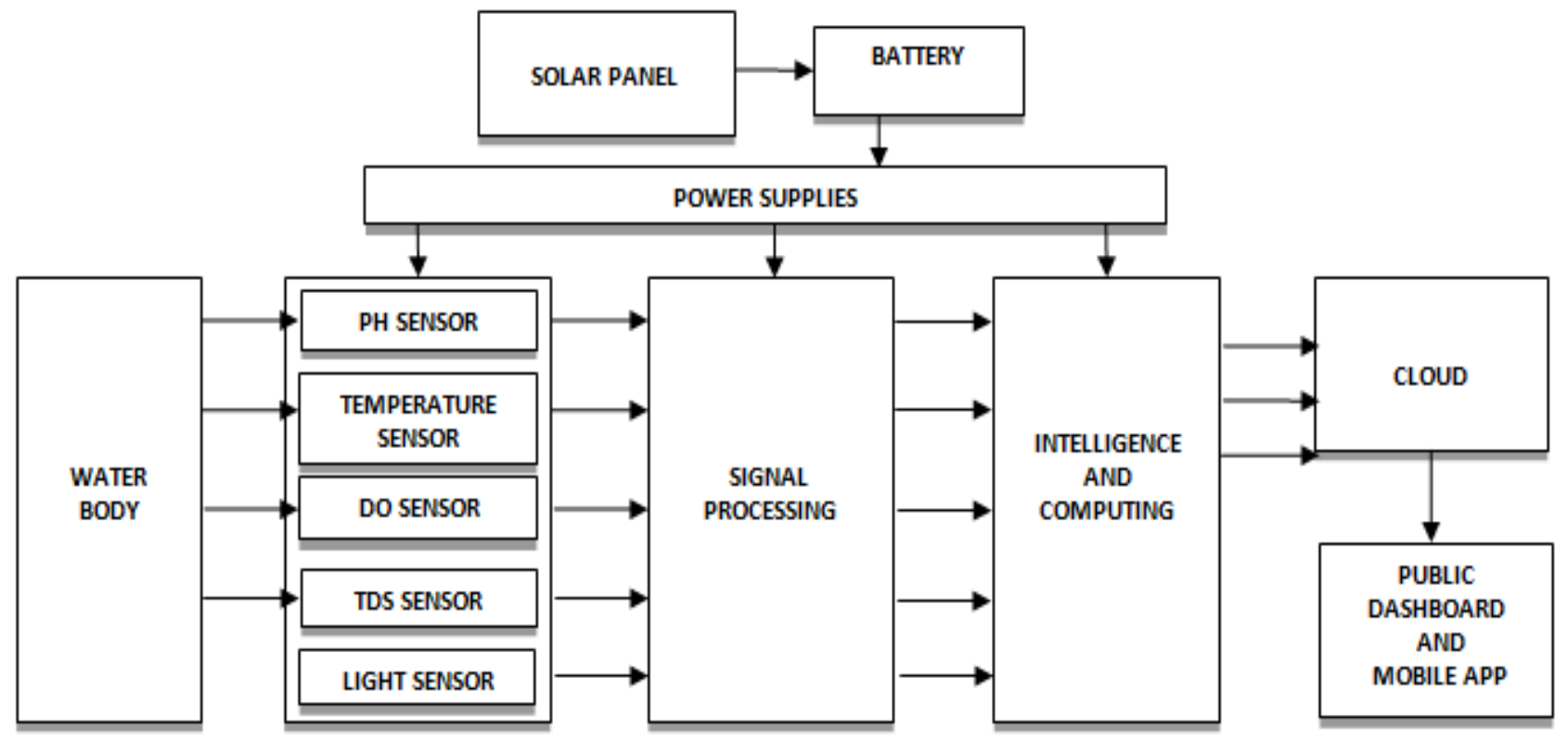

Fig 1: Block Diagram of Lake Water Quality Monitoring System

\section{i.pH sensor}

It has a plastic body and a gel filled electrode. The sensor is provided with a $\mathrm{SREF}+$ or $\mathrm{Ag} / \mathrm{AgCl}$ reference system. Its operating temperature range is between $0^{\circ} \mathrm{C}$ to $70^{\circ} \mathrm{C}$ and operating pressure upto $6 \mathrm{Bar}$ at $25^{\circ} \mathrm{C}$.

\section{ii. Temperature Sensor}

It is a digital thermo probe which can measure temperature between $-55^{\circ} \mathrm{C}$ to $+125^{\circ} \mathrm{C}$. Its Stainless steel probe head ensures high accuracy in harsh environmental conditions.

\section{iii.Dissolved Oxygen Sensor}

The sensor consists of a galvanic DO probe with PTFE membrane. It operates within a temperature range of $1^{\circ} \mathrm{C}$ to $60^{\circ} \mathrm{C}$ and can measure dissolved oxygen ranging in between 0 to $100 \mathrm{mg} / \mathrm{l}$ with an accuracy of $+/-0.05 \mathrm{mg} / \mathrm{l}$.

\section{iv. TDS sensor}

The TDS sensor is a conductivity cell whose cell constant is equal to $1.0 \mathrm{~cm}^{-1}$. It has 2 electrodes and an in-built automatic compensation.

\section{D.Signal Processing Circuits}

To amplify and filter the signals obtained from various sensors, the Lake Water Quality Monitoring System is equipped with the following signal conditioning circuits:

\section{i.TDS Conditioning Circuit}

It has an input voltage ranging in between 3.3 and $5.5 \mathrm{~V}$ and analog output voltage ranging between $0 \sim 2.3 \mathrm{~V}$. It is compatible with any $5 \mathrm{~V}$ or $3.3 \mathrm{~V}$ controller. It uses an

AC excitation source which prevents probe from polarization.

\section{ii.pH Conditioning Circuit}

The $\mathrm{pH}$ circuit requires an input voltage of 5.0V. Any $\mathrm{pH}$ Sensor with a BNC Connector can be interfaced with this circuit. It consists of Gain Adjustment Potentiometer to adjust the gain of the output signal.

\section{iii.DO Conditioning Circuit}

The DO conditioning circuit has two point calibration and supports any DO sensor with a galvanic probe.

\section{E.Intelligence And Computing Unit}

It comprises of following two microcontrollers:

\section{i.Arduino Nano}

It is a microcontroller board consisting of ATmega328 processor and has a small form factor. It has 8 analog input pins and 22 digital I/O pins out of which 6 pins are PWM pins and is based on AVR architecture.

\section{ii. NodeMCU}

NodeMCU Devkit 1.0 is microcontroller board with ESP-8266 32-bit at its core. It has built in Wi-Fi providing easy connectivity. It has 11 digital I/O pins, 1 analog input pin and has a clock speed of $80 \mathrm{MHz}$.

\section{CHALLENGES FACED AND ARCHITECTURAL IMPROVEMENTS}

The previous version of the system utilised a GSM module in order to establish a connection with the cloud. In doing so it consumed a lot of power. So, in order to extend the battery life, the new version now consists of NodeMCU board which has an in-built Wi-Fi module to connect with the cloud, as it consumed significantly less power.

The previous version also consisted of an optical turbidity sensor which no longer exists in the new version as it required frequent cleaning in order to get acceptable results, which was not feasible.

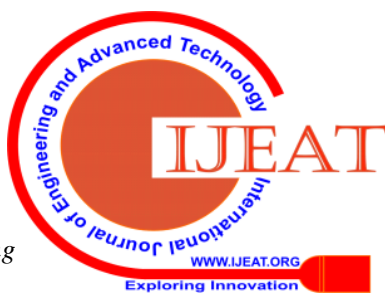




\section{SYSTEM FUNCTIONING}

Fig 1 illustrates the block diagram of lake water quality monitoring system. The sensors generate the data from the water body in real-time and feed it to their respective signal conditioning circuits, which perform the necessary amplification and filtering on the raw data so as to make it readable by the microcontrollers. The amplified data is then fed to an Arduino Nano which employs different algorithms to convert the raw data into meaningful values and is sent to a NodeMCU. The NodeMCU then pushes the data onto a dedicated cloud platform.

In order to extend the battery life, the NodeMCU frequently measures the ambient lighting conditions from a light sensor and optimizes the data transmission rate to the cloud. The intelligence algorithm continuously scans for any anomaly in water parameters and increases the data transmission rate upon detection.

The system is self-powered and runs on solar energy generated by a solar panel. A solar charge controller is connected to the solar panel which charges a lithium polymer battery, which in turn provides power to the whole system.

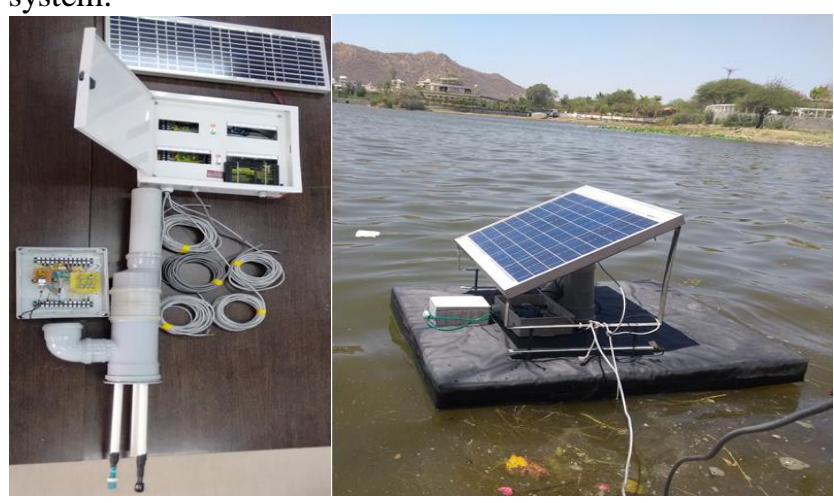

Fig 2.b: Undeployed System Fig 2.b: Deployed System

\section{RESULTS AND VERIFICATION}

Fig 2.a and Fig 2.b show the undeployed and deployed system respectively. The system was placed in 3 different lakes of Udaipur city, namely Fateh Sagar Lake, Pichola Lake, and Govardhan Sagar Lake, over different periods of time and the data was obtained. Samples were taken from these lakes in order to verify the results of the system by getting these samples tested at local laboratories, namely - Rahul laboratories, Anachem research laboratories and Udaipur Min-Tech Pvt. Ltd. By comparing the data obtained form the system with that from the laboratory, it can be easily deduced that the performance of the system is up to the mark.

Table 1 shows the comparison between the system's results versus those of local laboratories'.

Fig 3 shows the public dashboard which presents the live data of the proposed system deployed in lakes.

Fig 4.a, 4.b, 4.c, 4.d depict the graphical data of the water quality parameters available on the public dashboard.

Fig 5 shows the data available on the lake Monitoring System's Android App.

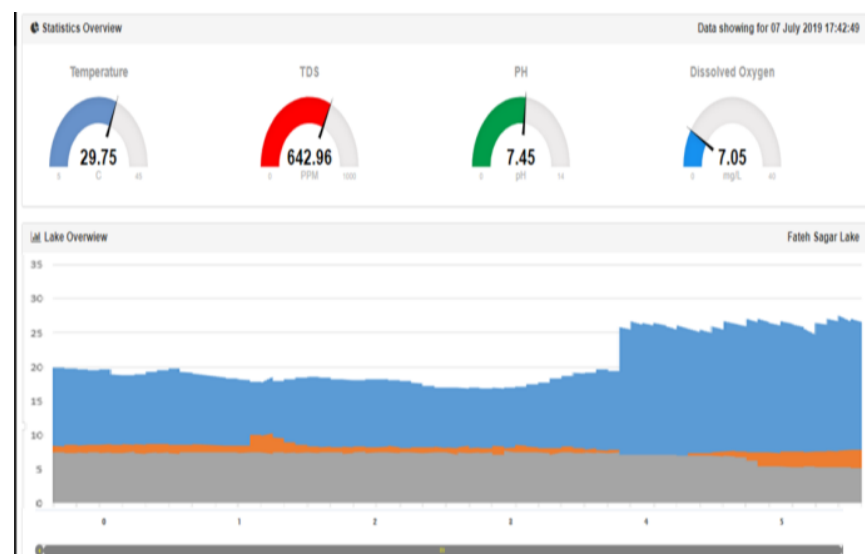

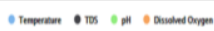

Fig 3 : Public Dashboard Of The Lake Water Quality Measuring System

Table 1 - Results Of The Proposed System Versus Results Of Local Laboratories

\begin{tabular}{|c|c|c|c|}
\hline Sample number & Parameters & $\begin{array}{c}\text { System } \\
\text { Results }\end{array}$ & $\begin{array}{c}\text { Laboratory } \\
\text { results }\end{array}$ \\
\hline \multirow{4}{*}{ Sample 1 } & $\mathrm{pH}$ & 6.89 & 6.98 \\
\cline { 2 - 4 } & Turbidity & $14 \mathrm{NTU}$ & $15 \mathrm{NTU}$ \\
\cline { 2 - 4 } & $\begin{array}{c}\text { Dissolved } \\
\text { oxygen }\end{array}$ & $18 \mathrm{ppm}$ & $19 \mathrm{ppm}$ \\
\hline \multirow{4}{*}{ Sample 2 } & pH & 7.23 & 7.26 \\
\cline { 2 - 4 } & Turbidity & $13 \mathrm{NTU}$ & $12 \mathrm{NTU}$ \\
\cline { 2 - 4 } & $\begin{array}{c}\text { Dissolved } \\
\text { oxygen }\end{array}$ & $17 \mathrm{ppm}$ & $17 \mathrm{ppm}$ \\
\hline \multirow{3}{*}{ Sample 3 } & Turbidity & $13 \mathrm{NTU}$ & $13 \mathrm{NTU}$ \\
\cline { 2 - 4 } & Dissolved & $17 \mathrm{ppm}$ & $18 \mathrm{ppm}$ \\
\cline { 2 - 4 } & oxygen & 7.31 & 7.28 \\
\hline
\end{tabular}

$\mathrm{pH}$

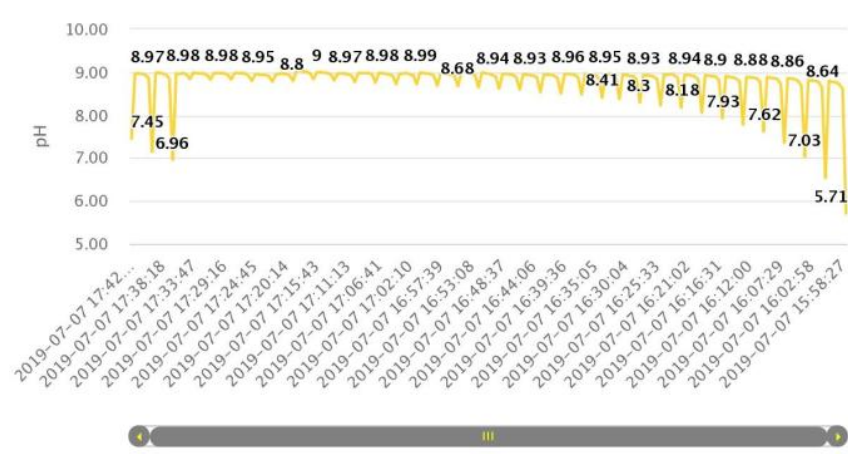

$\mathrm{pH}$

Fig 4.a : Graph For pH Values On Dashboard 


\section{Grade Sensors}

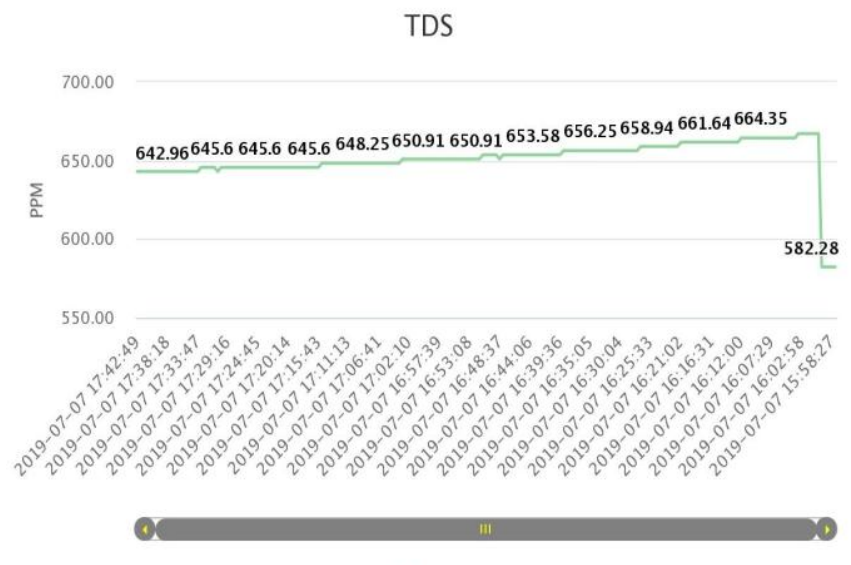

- TDS

Fig 4.b: Graph For TDS Values On Dashboard

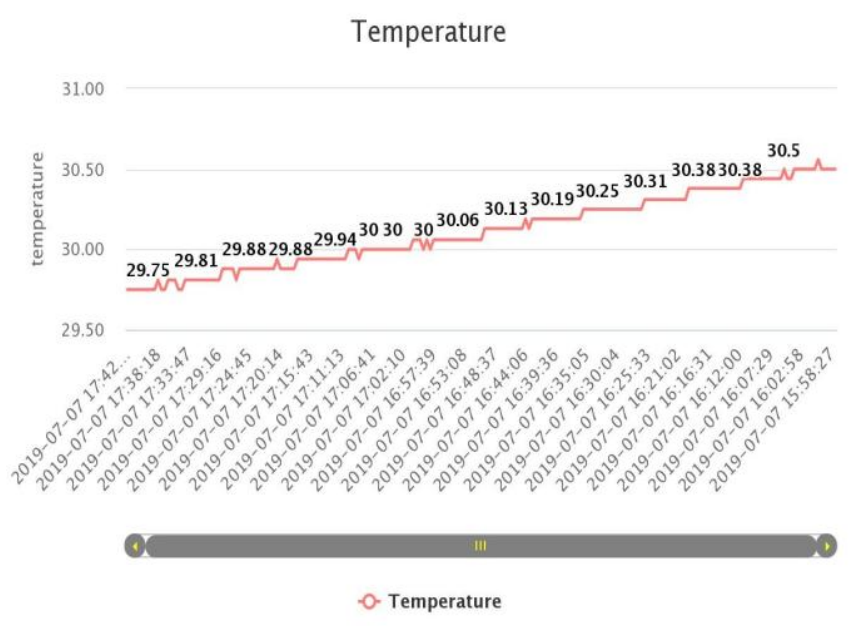

Fig 4.c: Graph For Temperature Values On Dashboard

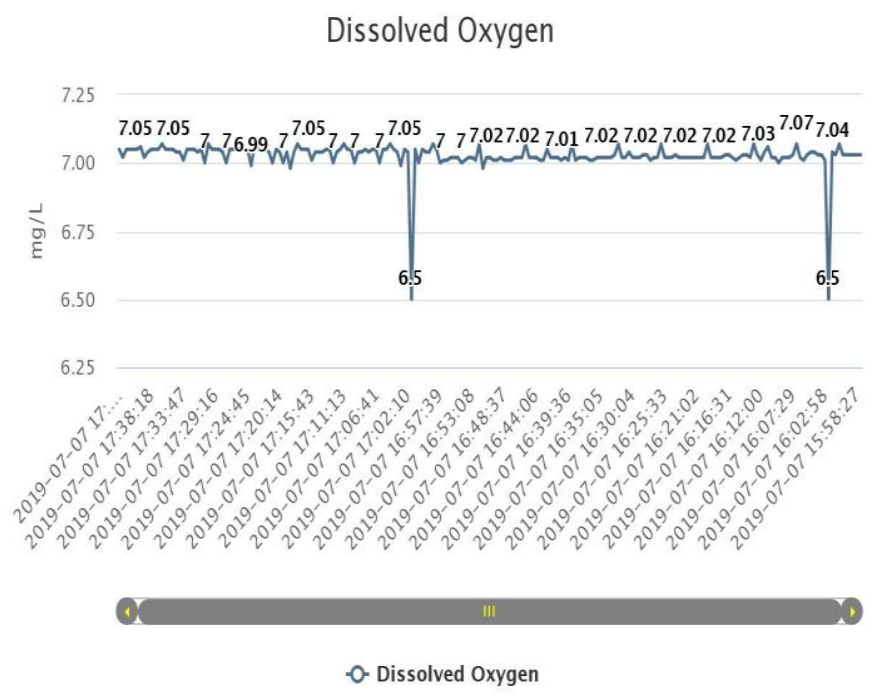

Fig 4.d: Graph For DO Values On Dashboard

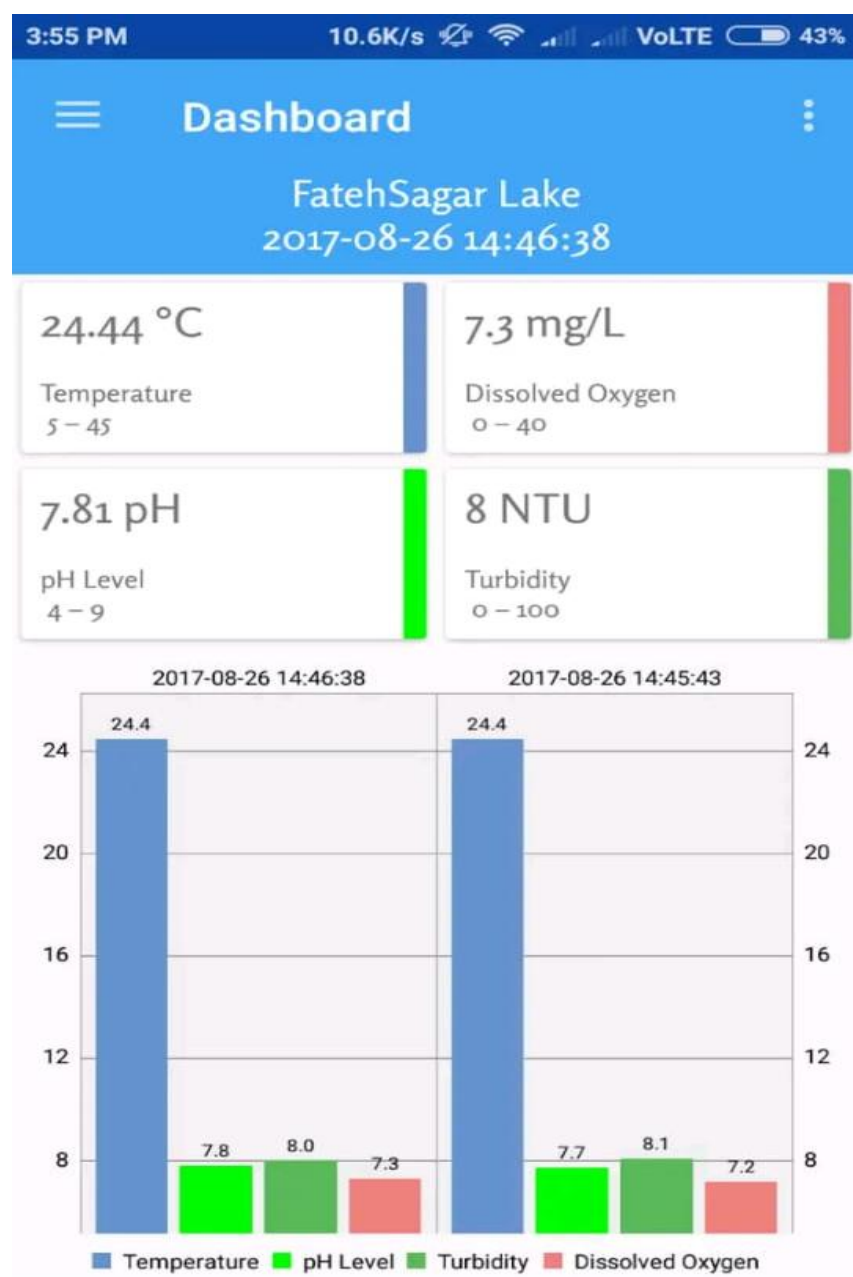

Fig 5 : Data Available On The Lake Monitoring System's Android App

\section{REFERENCES}

1. https://en.wikipedia.org/wiki/PH

2. https://en.wikipedia.org/wiki/Total_dissolved_solids

3. https://www.safewater.org/fact-sheets-1/2018/8/15/water-temperature-fa ct-sheet

4. www.enr.gov.nt.ca/sites/enr/files/dissolved_oxygen.pdf

5. https://www.safewater.org/fact-sheets-1/2017/1/23/tds-and-ph

6. Manoharan.S, Sathiyaraj.G, Thiruvenkadakrishnan.K, Vetriselvan.G.V, Praveenkishor," Water Quality Analyzer using IoT", International Journal of Innovative Technology and Exploring Engineering (IJITEE) ISSN: 2278-3075, Volume-8, Issue-8S, June 2019

7. Tha. Sugapriyaa, S. Rakshaya, K. Ramyadevi, M. Ramya, P.G. Rashmi, "SMART WATER QUALITY MONITORING SYSTEM FOR REAL TIME APPLICATIONS", International Journal of Pure and Applied Mathematics Volume 118 No. 20 2018, 1363-1369

8. Gokulanathan, S., et al. "A GSM Based Water Quality Monitoring System Using Arduino." Shanlax International Journal of Arts, Science and Humanities, vol. 6, no. 4, 2019, pp. 22-26.

9. S. I. Samsudin, S.I.M. Salim, K. Osman, S. F. Sulaiman, M. I. A. Sabri," A Smart Monitoring of a Water Quality Detector System", Indonesian Journal of Electrical Engineering and Computer Science Vol. 10, No. 3 , June 2018, pp. 951 958 ISSN: 2502-4752

10. R. Nithyanandam, T. W. Huan and N. H. T. Thy, "Case Studies: Analysis of Water Quality in Sungai Batu Ferringhi," Journal of Engineering Science and Technology, EURECA 2014 Special Issue, pp. 15 - 25, April 2015.

11. Z. Wang, Q. Wang, X. Hao, "The design of the remote water quality monitoring system based on WSN," in 2009 5th International Conference on Wireless Communications, Networking and Mobile Computing, 2009. pp. $1-4$.

Published By: 


\section{AUTHORS PROFILE}

Anupreet Dube is pursuing III year of her B.Tech. in Electronics and Communications at Techno India NJR Institute Of Technology, Udaipur(India). Her areas of interest are Internet Of Things and Embedded Systems.

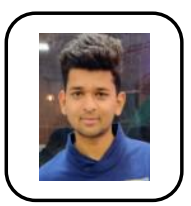

Jayesh Trivedi is pursuing III year of his B.Tech. in Electronics and Communications at Techno India NJR Institute Of Technology, Udaipur(India). His areas of interest are Embedded Systems and Artificial Intelligence at Edge.

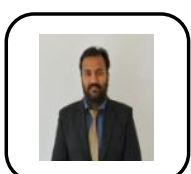

Yogendra Singh Solanki, is working as Asst. Professor Department of Electronics and Communications, Techno India NJR Institute of Technology, Udaipur. $\mathrm{He}$ is practicing the IoT Devices, AI/ML and VLSI in day to day life.

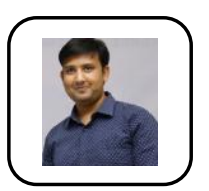

Aditya Maheshwari is working in the capacity of Project Lead- New Initiative \& Research at Techno India NJR Institute of Technology Udaipur. He is an Open Source Advocate, leading technical speaker and Expert of User Research (UI/UX). Leading students by creating and developing projects applying cloud technologies at an engineering institute. Achieved specialization and certification in IBM Watson and Blockchain, and applied in developing projects.

Abhishek Sharma, is working as Asst. Professor, Department of Mechanical Engineering, Techno India NJR Institute of Technology, Udaipur. His areas of interest are Industrial Internet Of Things and Designing of SolidWorks. 